\title{
CORRECTION
}

\section{Central diabetes insipidus emerging after steroid replacement in pituitary apoplexy}

CMAJ has been made aware of an error that occurred in the May 6, 2019, issue. ${ }^{1}$

In the third paragraph, the third sentence read, "She received hypotonic crystalloid solution and 1 dose of intravenous $100 \mu \mathrm{g}$ desmopressin." This should have read, "She received hypotonic crystalloid solution and 1 dose of oral $100 \mu \mathrm{g}$ desmopressin."

This has been corrected at cmaj.ca.

Cite as: CMAJ 2019 June 24;191:E716. doi: $10.1503 / \mathrm{cmaj} .190686$

\section{Reference}

1. Yang D, Newman SK, Katz K, et al. Central diabetes insipidus emerging after steroid replacement in pituitary apoplexy. CMAJ 2019;191:E501-4. 